\title{
No evidence for superiority of air or oxygen for neonatal resuscitation: a meta-analysis
}

\section{Aucune donnée probante n'appuie la supériorité de l'air ou de l'oxygène pour la réanimation néonatale: une méta-analyse}

\author{
Joanne Guay, MD $\cdot$ Jean Lachapelle, MD
}

Received: 28 March 2011/Accepted: 6 September 2011/Published online: 5 October 2011

(C) Canadian Anesthesiologists' Society 2011

\begin{abstract}
Purpose The aim of this meta-analysis was to re-evaluate the evidence in favour of oxygen or room air as the initial gas mixture for neonatal resuscitation in terms of the following outcomes: death, hypoxic/ischemic encephalopathy, need for tracheal intubation, and APGAR score-Appearance (skin color), Pulse (heart rate), Grimace (reflex irritability), Activity (muscle tone), and Respiration-at five minutes.

Methods A search with no language restriction for all available controlled clinical trials (CCT) was conducted in PUBMED, Cochrane Central Register of Controlled Trials, and EMBASE. Data were extracted independently by the two investigators.

Results Eight CCTs were retained for analysis. They included 1,500 patients, 772 in the oxygen group and 728 in the air group. The evidence is based mainly on quasirandomized studies $(1,311 / 1,500)$ with unblinded resuscitators $(1,421 / 1,500)$. The expertise/training of the resuscitators was unspecified for four of the eight studies. The risk ratio (RR) for death was 1.35 (95\% confidence intervals $[C I]=0.97$ to $1.88 ; P=0.08$; I-squared $0 \%$ ). The $R R$ for hypoxic/ischemic encephalopathy was 1.03 (95\% CI $=0.86$ to $1.23 ; P=0.74 ;$ I-squared $0 \%)$. The RR
\end{abstract}

J. Guay, MD ( $\square)$

Department of Anesthesiology, Maisonneuve-Rosemont Hospital, University of Montreal, 5415, L'Assomption Boulevard, Montreal, QC H1T 2M4, Canada

e-mail: joanne.guay@umontreal.ca

J. Lachapelle, MD

Department of Pediatrics, Maisonneuve-Rosemont Hospital,

University of Montreal, Montreal, QC, Canada for requiring a tracheal intubation was $0.85 \quad(95 \%$ $C I=0.69$ to 1.05 [random effects model]; $P=0.12$; I-squared $=9.51 \%$ ).

Conclusions The literature is insufficient to make any statement regarding the superiority of oxygen or room air as the initial gas mixture for neonatal resuscitation.

\section{Résumé}

Objectif L'objectif de cette méta-analyse était de réévaluer les données probantes soutenant la supériorité de l'oxygène ou de l'air ambiant en tant que mélange gazeux initial pour la réanimation néonatale en termes des critères suivants: décès, encéphalopathie hypoxique / ischémique, besoin d'intubation trachéale et score APGAR - Apparence (couleur de la peau), Pouls (fréquence cardiaque), Grimace (irritabilité réflexe), Activité (tonus musculaire) et Respiration - à cinq minutes. Méthode Une recherche sans restriction de langue a été réalisée dans les bases de données PUBMED, Cochrane Central Register of Controlled Trials et EMBASE afin de récupérer toutes les études cliniques contrôlées (ECC) disponibles. Les données ont été récupérées de façon indépendante par deux chercheurs.

Résultats Huit ECC ont été retenues pour analyse. Au total, elles portaient sur 1500 patients, dont 772 dans le groupe oxygène et 728 dans le groupe air. Les données probantes se fondent principalement sur des études quasi-randomisées (1311/1500) avec des réanimateurs non en aveugle (1421/1500). L'expertise / la formation des réanimateurs n'était pas spécifiée dans quatre des huit études. Le risque relatif $(R R)$ de décès était de 1,35 (intervalle de confiance [IC] $95 \%=0,97$ à 1,88 ; $P=0,08 ; \quad I$-carré $0 \%)$. Le $R R$ d'encéphalopathie hypoxique / ischémique était de 1,03 (IC $95 \%=0,86$ à 1,23; $P=0,74$; I-carré $0 \%$ ). Le RR de recours à une 
intubation trachéale était de 0,85 (IC $95 \%=0,69$ à 1,05 [modèle à effets aléatoires]; $P=0,12 ;$ I-carré $=9,51 \%$ ). Conclusion Les données de la littérature ne permettent pas d'émettre une recommandation quant à la supériorité de l'oxygène ou de l'air ambiant en tant que mélange gazeux initial à utiliser lors de la réanimation néonatale.

In their most recent publication, the American Heart Association recommended that neonatal resuscitation should be initiated with air if blended oxygen is not available. ${ }^{1}$ This recommendation is based mainly on the results of two meta-analyses. ${ }^{2,3}$ The first meta-analysis included five studies published during 1993 to 2003 . $^{2}$ The authors concluded, "There is insufficient evidence at present on which to recommend a policy of using room air over $100 \%$ oxygen, or vice versa, for newborn resuscitation." ${ }^{2}$ The second meta-analysis included seven studies published during 1993 to $2005 .^{3}$ The authors concluded, "Given the sum of the concerns regarding the methodology and patient population, it would be inappropriate to make definitive recommendations in North America based on the pooling of results from these studies." 3

The aim of the present meta-analysis was to re-evaluate the evidence in favour of oxygen or room air as the initial gas mixture for neonatal resuscitation with respect to the following outcomes: death, hypoxic/ischemic encephalopathy, need for tracheal intubation, and APGAR scoreAppearance (skin color), Pulse (heart rate), Grimace (reflex irritability), Activity (muscle tone), and Respiration-at five minutes.

\section{Methods}

A search with no language restriction was conducted in PUBMED on February 20, 2011 for all available controlled clinical trials (CCT), randomized (RCT) or quasi-randomized which compared oxygen $v s$ air as the initial gas mixture for neonatal resuscitation. The following search terms were used: "Randomis* OR Randomized trial* OR Double blind* OR Placebo* OR Clinical trial* OR Randomized OR Controlled Trial[Publication Type] OR Controlled clinical trial[Publication Type] OR Meta-analysis OR Review OR Systematic Review" [limit to human] AND "Air" AND "Infant, Newborn" AND "Asphyxia Neonatorum [*therapy]" OR "Oxygen Inhalation Therapy [adverse effects *methods]" OR "Resuscitation [*methods]" OR "Retinopathy of Prematurity [epidemiology]" OR "Bronchopulmonary Dysplasia [epidemiology]". We also searched the Cochrane Central Register of Controlled Trials (Clinical Trials) on May 2, 2011 using the following search terms: "Newborn [Search all text]" AND "Oxygen
[Search all text]" NOT "Animal [record title]" for any year and EMBASE [1980 to 2011 Week 17] with "Newborn [limit to human]" AND "Oxygen [limit to human]" AND "Resuscitation [limit to human- include all subheadings]". Reference lists of all studies as well as those of previous meta-analyses on the same topic ${ }^{2,3}$ were also checked.

Data were extracted from texts, tables, or figures independently by the two investigators as required. Conflicts $(n=1)$ were resolved by discussion. The latest available outcome up to 28 days was retained (taken earlier if some patients were lost to follow-up). The exact point at which the data were taken is shown in the Table 1 . When data were published in more than one report, the available reports were consulted, but the study (not the report) was considered the unit; therefore, no study was considered more than once. Data were analyzed with Comprehensive Meta Analysis version 2.2.044 (www. Meta-Analysis.com) and Review Manager (RevMan) version 5 (for the risk of bias assessment) (The Nordic Cochrane Centre, The Cochrane Collaboration, Copenhagen, Denmark). Studies were judged on the information contained in the reports without any assumption on the following: adequate sequence generation; allocation concealment (inability of the person who was recruiting the patient to know in advance to what group the patient would be assigned); blinding of the observer for the neurological status examination (hypoxic/ ischemic encephalopathy); incomplete outcome data addressed (clear description of the fate of all patients eligible/ included in the study and of all outcomes); free of selective reporting (outcomes of interest clearly available for all patients included in the study); and free of other bias (any other possible factor that could have influenced the results, including any obvious potential commercial interest). Heterogeneity was assessed by the I-squared value. Numbers needed to treat or harm were calculated on the odds ratios (http://www. nntonline.net/visualrx/). Publication bias was assessed with the classical fail-safe number, the number of missing studies required to bring the $P$ value to 0.05 .

\section{Results}

The flow diagram of the study selection is provided in Fig. 1. The eight studies retained for analysis included 1,500 patients, 772 in the oxygen group and 728 in the air group. $^{4-12}$ The exact distribution per country cannot be given because 18 patients originally reported by Saugstad et $a l .{ }^{8}$ were counted twice and need to be subtracted; nevertheless, as originally reported, the distribution would be: India $=1,148$; Egypt $=121$; Philippines $=26$; Estonia $=26 ; \quad$ Spain $=85 ; \quad$ Denmark $=69 ; \quad$ Norway $=2$; United States $=41$. The risk of bias assessment is given in Fig. 2. The characteristics of the studies are detailed in the 


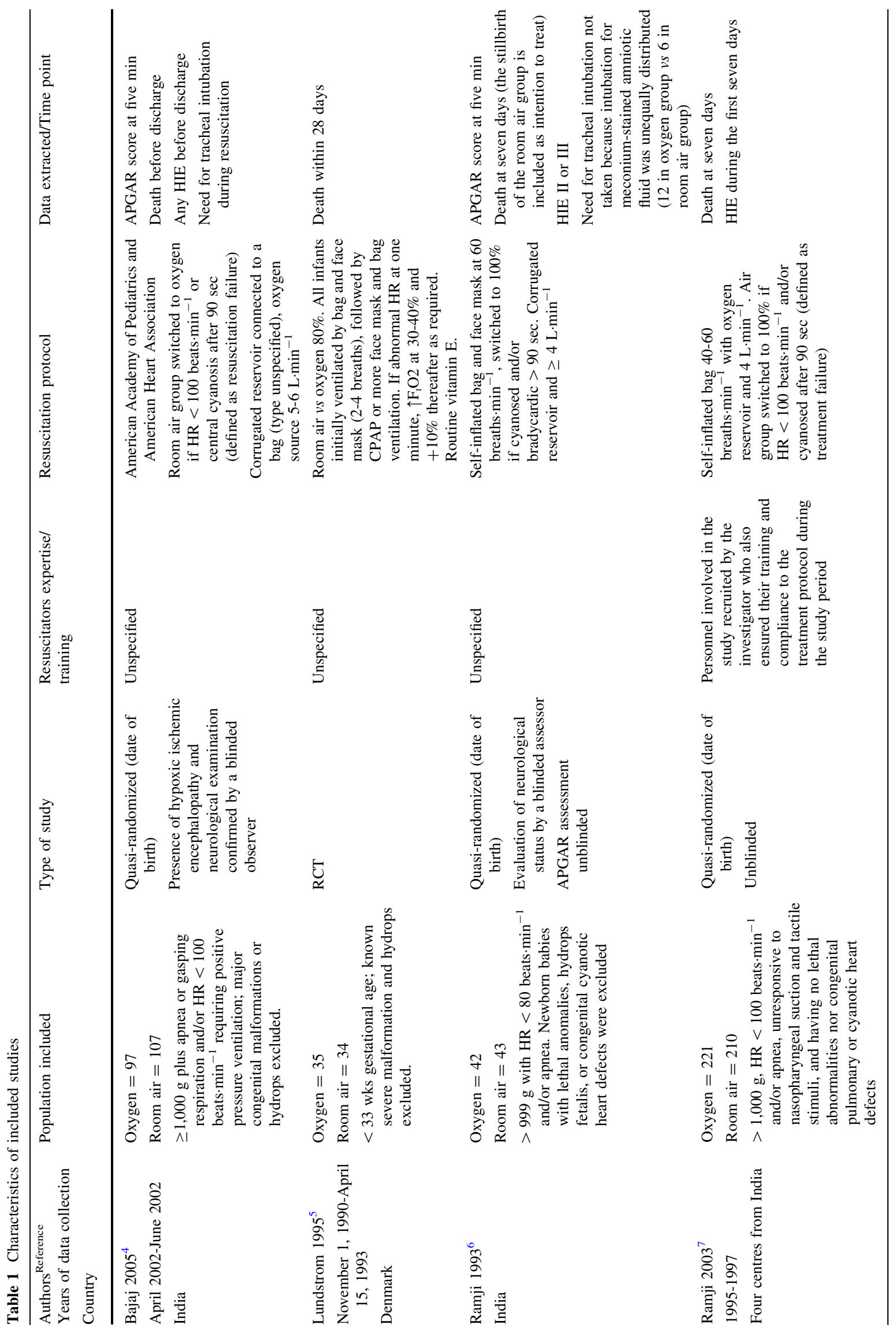




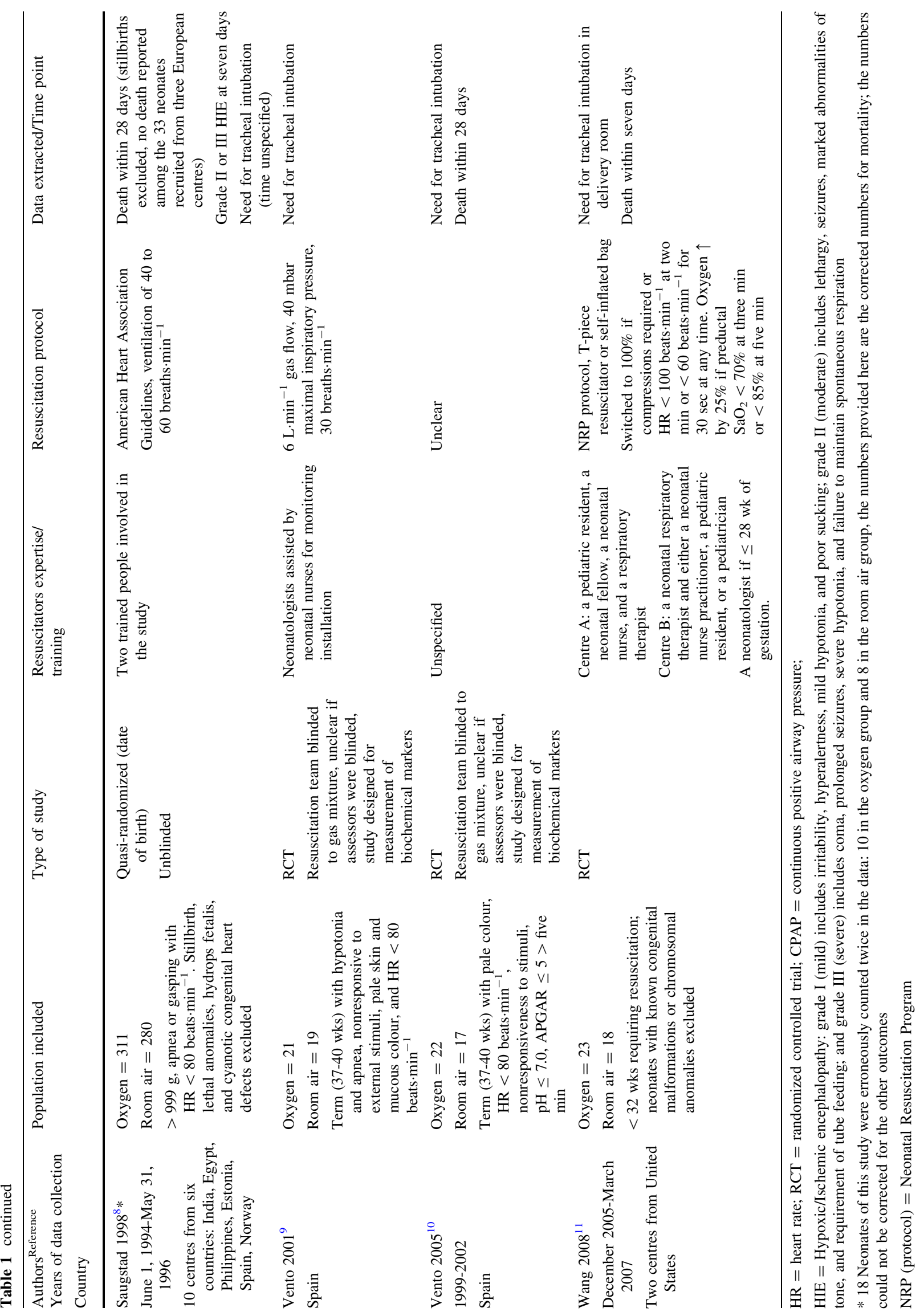


Fig. 1 Flow diagram of the study selection. $\mathrm{CCT}=$ controlled clinical trial (randomized or quasirandomized)
Flow diagram of the study selection

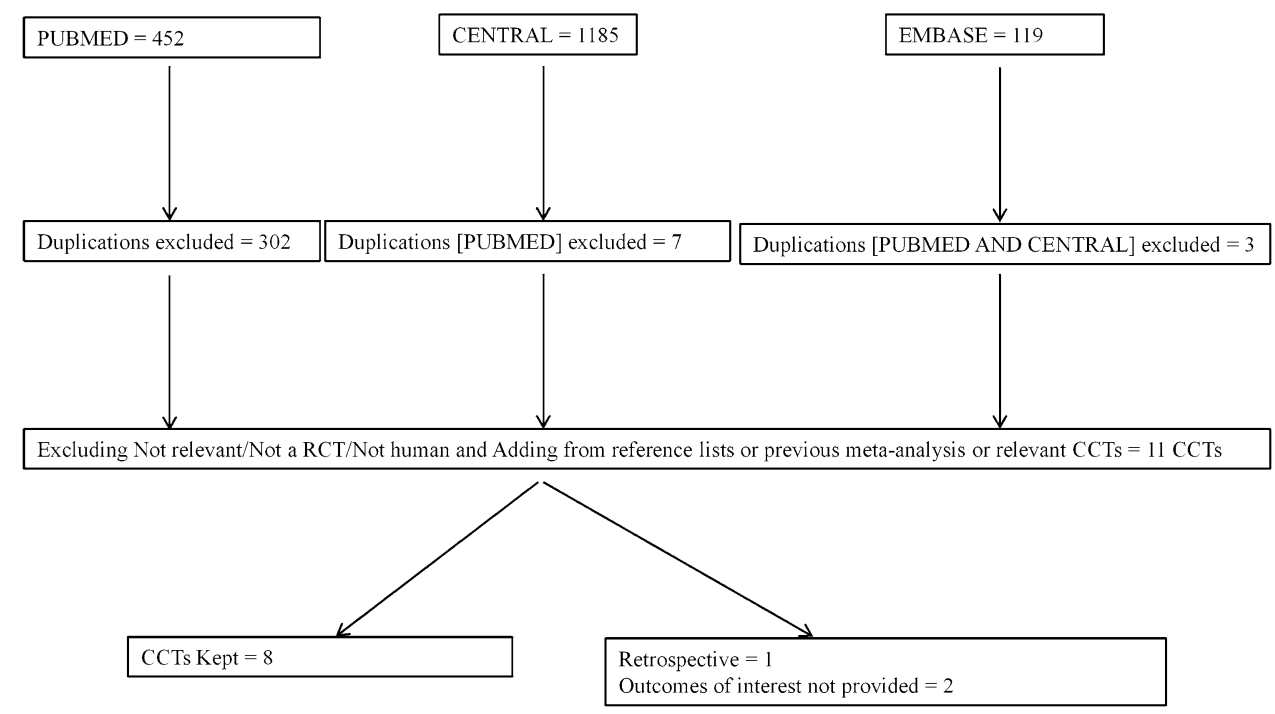

Table 1. Four studies were quasi-randomized (allocation according to the date of birth [even $v s$ odd]). ${ }^{4,6-8}$ One study mentioned that neonates for whom spontaneous circulation was never achieved were considered stillbirths and were excluded from the analysis. ${ }^{8}$ For that study, deaths included in the analysis occurred only in non-European countries. ${ }^{8}$ Of the four potentially randomized studies (three were said to be randomized, but the exact method was unspecified), three were not designed for clinical outcomes. ${ }^{5,9,10}$ In the study by Bajaj et al., ${ }^{4}$ the neurological examination at discharge for the survivors in the room air group is missing for 15 patients, while all such data are given for the survivors in the oxygen group. For this study, an abnormal neurological examination at discharge was found in $13.8 \%$ of survivors available for follow-up in the oxygen group and $20.0 \%$ of the survivors in the room air group. Data retained for this study were any evidence of hypoxic/ ischemic encephalopathy before discharge. No obvious methodological problem was detected for this outcome.

In the oxygen group, the risk ratio (RR) bordered the significance level for an increased risk of death $(\mathrm{RR}=1.37$; $95 \%$ confidence interval $[\mathrm{CI}]=1.08$ to $1.75 ; P=0.01$; I-squared $0 \%$ ). The number needed to harm (NNTH) is 20 (95\% CI $=93$ to 10$)$, classical fail safe number is 2 . Excluding the study where the number of true failed resuscitations (spontaneous circulation never achieved) was not counted, ${ }^{8}$ the RR would be 1.35 (95\% CI $=0.97$ to 1.88 ; $P=0.08$; I-squared 0\%) (Fig. 3). There was no difference in the risk for hypoxic/ischemic encephalopathy $(\mathrm{RR}=1.03 ; 95 \% \mathrm{CI}=0.86$ to $1.23 ; P=0.74$; I-squared 0\%) (Fig. 4). Excluding the study by Bajaj et al., ${ }^{4}$ the RR would be 1.05 (95\% CI $=0.79$ to $1.39 ; P=0.74$; I-squared 0\%). Excluding both the Bajaj et al. ${ }^{4}$ and Saugstad et al. ${ }^{8}$ studies, the RR for hypoxic/ischemic encephalopathy would
Risk of Bias

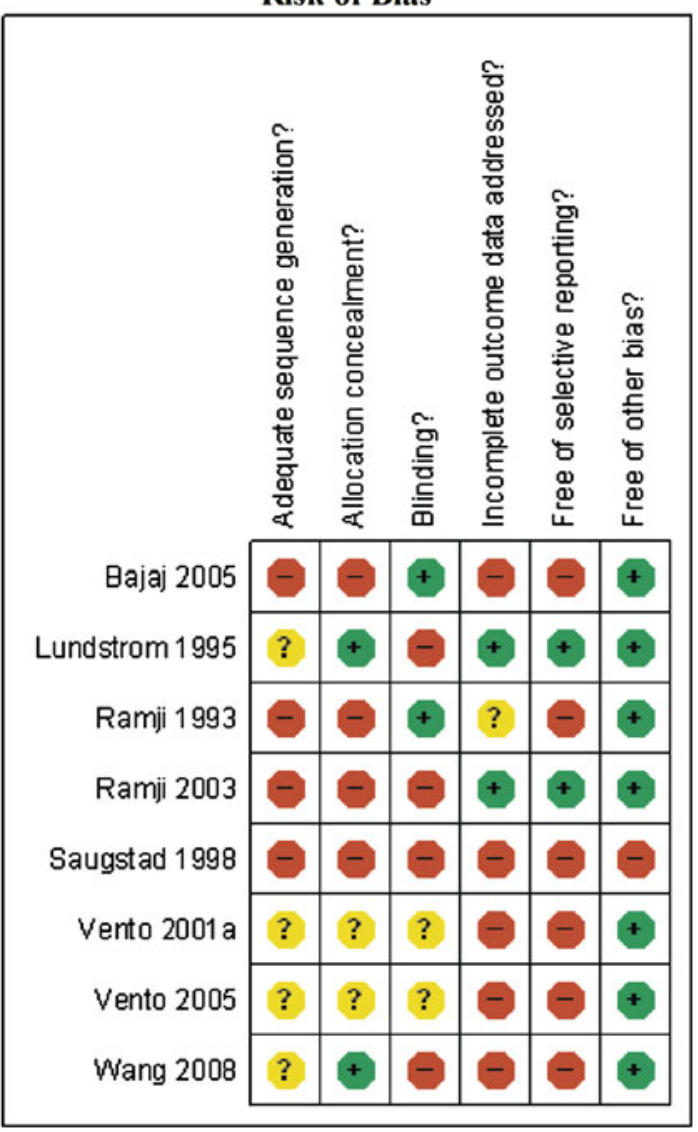

Fig. 2 Risk of bias assessment. Blinding was judged as adequate if the examination for hypoxic/ischemic encephalopathy was performed by an assessor blinded to the treatment group

be $\mathrm{RR}=1.03(95 \% \mathrm{CI}=0.81$ to $1.32 ; P=0.82 ; \mathrm{I}$-squared $0 \%) \quad(n=516$ patients; $\quad$ oxygen $=263$ and room air $=253$-all derived from the same authors). ${ }^{6,7}$ The risk 
Fig. 3 Risk ratio for death. The difference was not statistically significant when the study of Saugstad et al. (where neonates who never achieved spontaneous circulation where excluded from the results) was excluded

\section{Death up to 28 days}

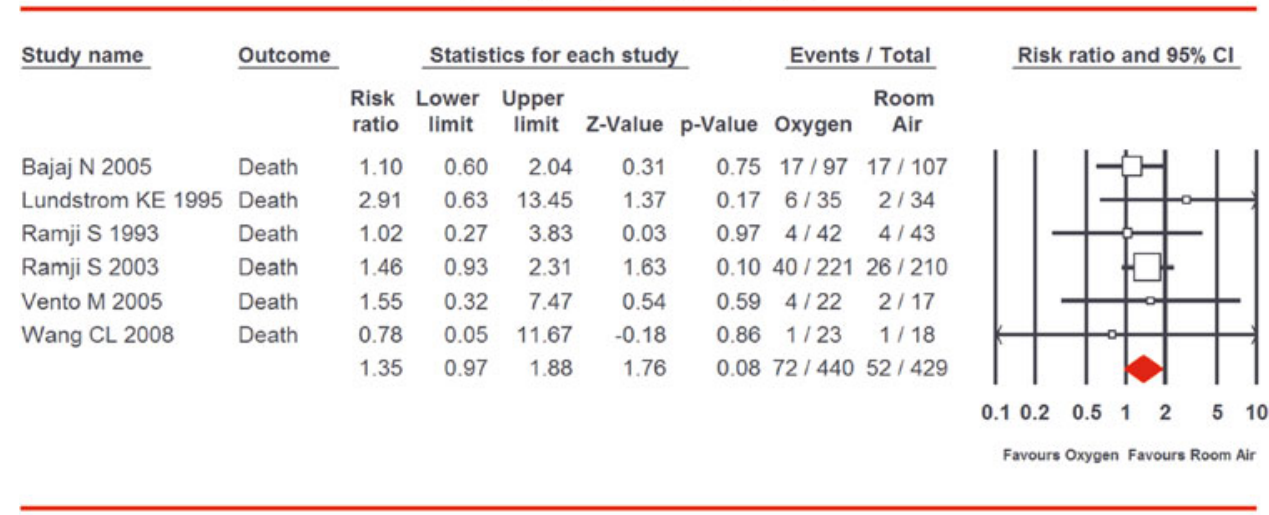

Meta Analysis: I-squared $=0 \%$

\section{Hypoxic/ischemic Encephalopathy}

4 There was no difference in the risk ratio of hypoxic/ ischemic encephalopathy
Fig. 5 The risk ratio for requiring endotracheal intubation
Needed Tracheal Intubation

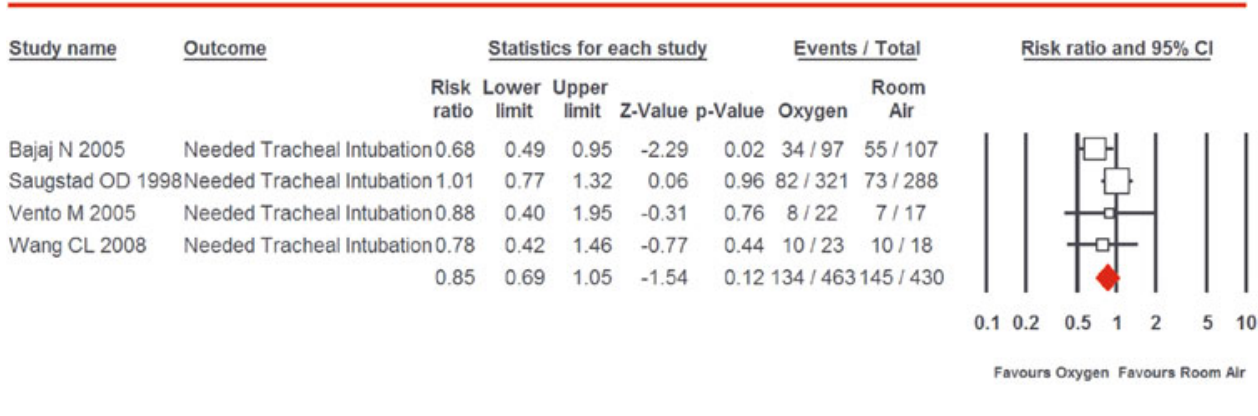

Meta Analysis: Random Effects Model; I-squared=9.51\% of requiring a tracheal intubation was similar for the two treatment groups (RR $0.85 ; 95 \% \mathrm{CI}=0.69$ to 1.05 [random effects model]; $P=0.12$; I-squared $=9.5 \%$ ) (Fig. 5). Data for the APGAR score at five minutes could be extracted for only two studies (288 patients); one study favoured oxygen and the other favoured room air. An attempt to sum them would give heterogeneity of $83.6 \%$ (I-squared value). A follow-up at 18-24 months (not formally blinded) is available for the study of Saugstad et al. ${ }^{8}$ representing $69 \%$ of the patients resuscitated with oxygen and $62 \%$ of those resuscitated with room air. In those infants with no followup, the room air group had a significantly lower heart rate at $90 \mathrm{sec}$ of life than those resuscitated with oxygen (median 100 beats $\min ^{-1} ; 5$ to $95 \% \mathrm{CI}=68$ to 147 vs 120 beats. $\mathrm{min}^{-1} ; 5$ to $95 \% \mathrm{CI}=60$ to 166$)$. The incidence of cerebral palsy was $7 \%$ and $10 \%$ for oxygen and room air, respectively $\quad(\mathrm{RR}=0.75 ; 95 \% \quad \mathrm{CI}=0.31$ to 1.80 ; $P=0.52$ ), and the incidence of abnormal development was $10 \%$ and $15 \%$ for oxygen and room air, respectively $(\mathrm{RR}=0.64 ; 95 \% \mathrm{CI}=0.31$ to $1.32 ; P=0.22) .{ }^{12}$ 


\section{Discussion}

The available literature is clearly insufficient to make any statement regarding on the superiority of air or oxygen as the initial gas mixture for neonatal resuscitation. The evidence is based mainly on quasi-randomized studies $(1,311 /$ $1,500)$ with unblinded resuscitators $(1,421 / 1,500)$. The expertise/training of the resuscitators was unspecified for four of the eight studies. ${ }^{4-6,10}$ One study ${ }^{8}$ excluded from the count of deaths those neonates for whom a spontaneous circulation was never achieved (true failed resuscitation). This ought to be considered as a major flaw. In an intention-to-treat analysis, those deaths should have been retained in their allocated group for the final analysis. It is possible here that the sicker neonates, those who needed a more vigorous resuscitation, were simply excluded from the results. Excluding this study, no difference in risk of death can be demonstrated between the two treatments (oxygen $v s$ room air). For this study, all recorded deaths occurred in non-European countries. ${ }^{8}$ In the present metaanalysis, a high percentage of the patients were recruited in India. The perinatal (stillbirth plus early neonatal mortality) death rate in India is 49 per 1,000 pregnancies. ${ }^{13}$ The perinatal death rate in Canada from 1999 to 2003 was 6.3 per $1,000(95 \% \mathrm{CI}=6.2$ to 6.4$) .{ }^{14}$ Clearly, there are factors other than the initial gas mixture used for neonatal resuscitation (room air or oxygen) that can make a substantial difference in neonatal mortality. Therefore it is doubtful that the data collected in India apply to Canada and similar countries.

The present meta-analysis contains studies that mix premature and term babies, clearly mixing two different populations with different physiology, different morbidity, and different mortality rate. ${ }^{15}$ An unstratified analysis may lead to spurious results (Simpson's paradox). Finally, if the two large studies containing major flaws ${ }^{4,8}$ are excluded, we then encounter the issue of the "small-study effect". ${ }^{16}$ The small-study effect has two major aspects: contribution to heterogeneity and the publication bias. Heterogeneity was not a problem in the present meta-analysis. It is well recognized, however, that small studies are more likely to be published when there are positive (statistically significant) rather than negative (not statistically significant) results; this is part of the "publication bias". To assess the potential influence of this problem, several techniques have been proposed, e.g., the "Trim and Fill" technique. This technique simply imputes values to the potentially missing studies (for instance the small negative ones), thus allowing an estimate of what the effect size would be if these small studies were published and included. Since this technique requires at least about 20 studies, it could not be applied here. Instead, we have used the classical fail-safe number on the effect on mortality. In the room air group, the RR for death was statistically significantly lower only when all studies were included (including those with major flaws). We then see that only two missing studies would be enough to bring this $P$ value to 0.05 (not statistically significant). This shows the extreme uncertainty of this alleged difference in mortality between room air and $100 \%$ oxygen.

An appropriate study on the effect of oxygen $v s$ room air on mortality should therefore be conducted in countries with a low perinatal death rate using a stratified analysis (term $v s$ preterm neonates) and a sample size large enough to provide an appropriate power. Considering a perinatal mortality rate of $0.6 \%$ in Canada, 39,046 neonates $(19,523$ per group) would be required to prove or disprove a onethird reduction in mortality (from $0.6 \%$ to $0.4 \%$ ) with an alpha value of 0.05 and a beta value of 0.2 (two-sided test) (http://www.stat.ubc.ca/ rollin/stats/ssize/b2.html).

In the present meta-analysis, there was no difference in the rate of hypoxic/ischemic encephalopathy (RR 1.03; $95 \% \mathrm{CI}=0.86$ to 1.23 ) among the survivors at the shortterm evaluation, suggesting that the two treatment modalities could be equivalent and there would be no ethical contraindications to a large multicentre trial. However, subtle neurological abnormalities are not always easy to detect in the first few months of life. A trend towards a onethird reduction in the incidence of neurological abnormalities (cerebral palsy/developmental delay) at 20 months in the Resair 2 study raises serious concerns on the use of room air. ${ }^{12}$ The large number of patients lost to follow-up in this study, however, makes these results difficult to interpret. The percentage of patients lost to follow-up was similar across the two treatment groups but twice as high as the percentage of patients suffering from a neurological abnormality. Patients lost to follow-up in the room air group had a lower heart rate at $90 \mathrm{sec}$ than those lost to follow-up in the oxygen group. Therefore, patients lost to follow up in the room air group might have been more severely asphyxiated than those lost to follow-up in the oxygen group. Hence those results may even underestimate the difference between the two groups in the incidence of neurological abnormalities at 20 months.

In North America, the incidence of cerebral palsy is estimated at 1.4/1,000 deliveries. ${ }^{17}$ Thus, the sample size of a study trying to determine a difference between room air and oxygen in the overall incidence of cerebral palsy would be much higher than the one needed to look for a difference in the death rate. In their study, Wang et al. reported that the incidence of grade III-IV intraventricular hemorrhage was $11 \%(2 / 18)$ in the room air group and $0 \%(0 / 23)$ in the $100 \%$ oxygen group, with a similar mortality in both groups (1/18 vs 1/23 for room air and $100 \%$ oxygen, respectively). ${ }^{11}$ Based on this single small study, we can infer that 570 preterm neonates would be required to attempt to eliminate a difference of 5\% (alpha value of 
0.05 , beta value of 0.2 , and two-sided test) in the incidence of severe intraventricular hemorrhage. However, considering that neither Wang et al. nor Escrig et al. were able to stabilize premature newborns with room air, we are of the view that room air should not be the initial gas mixture used for resuscitation of premature newborns. ${ }^{11,18}$

The trend towards a reduction in the number of patients who require tracheal intubation (RR $0.85 ; 95 \% \mathrm{CI}=0.69$ to 1.05 ) if oxygen is used should be interpreted cautiously because the expertise/training of the resuscitators was not mentioned in half of the studies, and the resuscitators were blinded to the gas mixture for only two studies.

First reported in 1952, the APGAR score has gone through various periods of favour and disfavour; it has been criticized as having a poor inter-rater reliability and a poor calibration when used as an isolated criterion to predict mortality and long-term morbidity, particularly in preterm newborns. ${ }^{19}$ The relationship between the five minute APGAR score and long-term neurological outcome is too fragile to base any evaluation of a resuscitation protocol on it, and future studies should not consider the five minute APGAR score as a final outcome. Finally, even if air were chosen as the first gas mixture, due to the high number of neonates who were switched to oxygen during these studies (approximately 25\%), supplementary oxygen should continue to be made available., ${ }^{2,3}$

In conclusion, the literature is insufficient to make any statement regarding the superiority of oxygen or room air as the initial gas mixture for neonatal resuscitation.

Disclosure Access to some of the references was provided by University of Montreal. We have no other relevant disclosure.

Competing interests None declared.

\section{References}

1. Kattwinkel J, Perlman JM, Aziz K. et al.; American Heart Association. Neonatal resuscitation: 2010 American Heart Association Guidelines for Cardiopulmonary Resuscitation and Emergency Cardiovascular Care. Pediatrics 2010; 126: e1400-13.

2. Tan A, Schulze A, O'Donnell CP, Davis PG. Air versus oxygen for resuscitation of infants at birth. Cochrane Database Syst Rev 2005; (2): CD002273.
3. Rabi Y, Rabi D, Yee W. Room air resuscitation of the depressed newborn: a systematic review and meta-analysis. Resuscitation 2007; 72: 353-63.

4. Bajaj N, Udani RH, Nanavati RN. Room air vs. 100 per cent oxygen for neonatal resuscitation: a controlled clinical trial. J Trop Pediatr 2005; 51: 206-11.

5. Lundstrom KE, Pryds O, Greisen G. Oxygen at birth and prolonged cerebral vasoconstriction in preterm infants. Arch Dis Child Fetal Neonatal Ed 1995; 73: F81-6.

6. Ramji S, Ahuja S, Thirupuram S, Rootwelt T, Rooth G, Saugstad $O D$. Resuscitation of asphyxic newborn infants with room air or 100\% oxygen. Pediatr Res 1993; 34: 809-12.

7. Ramji S, Rasaily R, Mishra PK, et al. Resuscitation of asphyxiated newborns with room air or $100 \%$ oxygen at birth: a multicentric clinical trial. Indian Pediatr 2003; 40: 510-7.

8. Saugstad $O D$, Rootwelt $T$, Aalen $O$. Resuscitation of asphyxiated newborn infants with room air or oxygen: an international controlled trial: the Resair 2 study. Pediatrics 1998; 102: e1.

9. Vento M, Asensi M, Sastre J, García-Sala F, Pallardo FV, Vina J. Resuscitation with room air instead of $100 \%$ oxygen prevents oxidative stress in moderately asphyxiated term neonates. Pediatrics 2001; 107: 642-7.

10. Vento M, Sastre J, Asensi MA, Vina J. Room-air resuscitation causes less damage to heart and kidney than $100 \%$ oxygen. Am J Respir Crit Care Med 2005; 172: 1393-8.

11. Wang CL, Anderson C, Leone TA, Rich W, Govindaswami B, Finer NN. Resuscitation of preterm neonates by using room air or $100 \%$ oxygen. Pediatrics 2008; 121: 1083-9.

12. Saugstad $O D$, Ramji $S$, Irani $S F$, et al. Resuscitation of newborn infants with $21 \%$ or $100 \%$ oxygen: follow-up at 18 to 24 months. Pediatrics 2003; 112: 296-300.

13. World Health Organization, Department of making pregnancy safer, Country profile: India. ORC Macro, 2007. MEASURE DHS STATcompiler. http://www.measuredhs.com, October 8 2008. Available from URL: http://www.who.int/entity/making pregnancy_safer/countries/ind.pdf (accessed March 2011).

14. Statistics Canada. Available from URL: http://www.statcan.gc.ca (accessed March 2011).

15. Simpson CD, Ye XY, Hellmann J, Tomlinson C. Trends in causespecific mortality at a Canadian outborn NICU. Pediatrics 2010; 126: e1538-44.

16. Rucker G, Schwarzer G, Carpenter JR, Binder H, Schumacher M. Treatment-effect estimates adjusted for small-study effects via a limit meta-analysis. Biostatistics 2011; 12: 122-42.

17. Gilbert WM, Jacoby BN, Xing G, Danielsen B, Smith LH. Adverse obstetric events are associated with significant risk of cerebral palsy. Am J Obstet Gynecol 2010; 203: 328.e1-5.

18. Escrig R, Arruza L, Izquierdo I, et al. Achievement of targeted saturation values in extremely low gestational age neonates resuscitated with low or high oxygen concentrations: a prospective, randomized trial. Pediatrics 2008; 121: 875-81.

19. Bharti B, Bharti $S$. A review of the Apgar score indicated that contextualization was required within the contemporary perinatal and neonatal care framework in different settings. J Clin Epidemiol 2005; 58: 121-9. 